\title{
Population Turnover and the Growth of Urban Areas
}

\author{
By Jason P. Brown and Colton Tousey
}

$\mathrm{P}$ eople in the United States are relocating nearly half as much as they did in the early 1980s. A decline in relocations may make roeconomic conditions and in the industry composition of various regions of the country. When people move across regions for job-related reasons, they may help smooth out changes that hit certain labor markets harder than others. As a result, a decline in relocations may also indicate a decline in labor market adjustment across industries and occupations. For example, some areas of the Rust Belt hit hard by the decline in U.S. manufacturing were unable to compensate for the associated employment losses by reallocating displaced workers to other locations or regions. Over time, areas with less labor market adjustment may experience slower growth.

One way to measure labor market adjustment is through population turnover - the propensity of people to move into and out of a given location. Just as business turnover can fuel economic growth by allowing new firms to replace older and potentially less efficient firms, population turnover can bring new ideas into an area or spread existing ideas elsewhere. In addition, population turnover may lead to better

\footnotetext{
Jason P. Brown is a research and policy officer at the Federal Reserve Bank of Kansas City. Colton Tousey is an assistant economist at the bank. This article is on the bank's website at www.KansasCityFed.org
} 
matches between employer and employee, an important factor in the growth of urban areas.

In this article, we document the relationship between population turnover and overall population growth across urban areas of various sizes from 2000 to 2017. We find that larger urban areas tend to have higher population turnover. In addition, we find that higher initial levels of turnover are correlated with faster population growth over the subsequent decades. Persistent differences in both the level and composition of population turnover between urban areas are a proxy for differences in labor market adjustment and help explain faster population growth in larger urban areas. Our findings are consistent with previous studies showing economic activity increasingly concentrating in the country's larger urban areas (Glaeser 2011; Moretti 2012).

Section I documents differences in population turnover across small, medium, and large urban areas. Section II explores the relationship between population turnover and long-term population growth and discusses the potential implications for urban areas.

\section{Domestic Migration and Population Turnover in the United States}

Moves within the United States-hereafter, "domestic migration"- are often viewed as a crucial component of labor market adjustment. For example, several studies show that domestic migration helps smooth out macroeconomic shocks or structural changes to regionspecific industries such as manufacturing and agriculture (Blanchard and Katz 1992; Partridge and Rickman 2006; Dennis and Iscan 2007; Partridge and others 2012).

However, domestic migration may play a smaller role in this adjustment now than in the past. Dao, Furceri, and Loungani (2017) find that net migration (moves in minus moves out) is less responsive to local demand shocks compared with previous decades. In addition, recent analyses of local labor market adjustment after China's entrance into the World Trade Organization generally find that large adverse shocks have small effects on local population or out migration (Autor, Dorn, and Hanson 2013; Autor and others 2014).

The potential diminished role of domestic migration in smoothing out labor market shocks may be a result of the overall decline in 
domestic migration over the past several decades. Chart 1 shows the domestic migration rate from 1947 to 2017 using information collected by the U.S. Census Bureau and cosponsored by the Bureau of Labor Statistics. The migration rates are based on self-reported moves in the Current Population Survey's Annual Social and Economic Supplement (ASEC). In the mid-1980s, nearly 20 percent of people reported moving in the prior year. However, by 2017, the domestic migration rate had fallen by half to 9.8 percent.

While other studies have documented these trends, few have offered explanations for them (Molloy, Smith, and Wozniak 2011; Molloy and Smith 2019; Frey 2019). Kaplan and Schulhofer-Wohl (2017) suggest the decline may be the result of less geographically differentiated compensation for occupations, combined with an increase in workers' awareness of that fact. Other common explanations include an aging population and the rise of dual-earner households, which may be less likely to move if both earners cannot secure employment in a destination. Dual-earner households may play an especially large role in domestic migration in large urban areas, where they are more likely to find better job matches. Consistent with this explanation, Molloy and Smith (2019) find that both in- and out-migration rates are higher on average in areas with stronger labor demand than in areas with weaker demand. However, to date, little research has examined domestic migration across urban areas of various size or how the overall trend in domestic migration may differ across urban areas.

To capture these overall trends, we consider a broader measure of domestic migration that accounts for population turnover-moves into plus moves out of a given area. The rate of population turnover in an urban area provides an ideal proxy for labor market adjustment.

One of the limitations of some of the prior research on domestic migration is the lack of geographical coverage in the ASEC data. To capture differences in population turnover across urban areas of various size, we use county-level tabulations of domestic migration based on income tax filings provided by the Internal Revenue Service (IRS) Statistics of Income (SOI). The SOI data capture the inflow and outflow of people from one county to another across the entire country and can be tabulated for both households and individuals. The number of returns filed approximates the number of households that migrated, while the 


\section{Chart 1}

U.S. Domestic Migration Rate

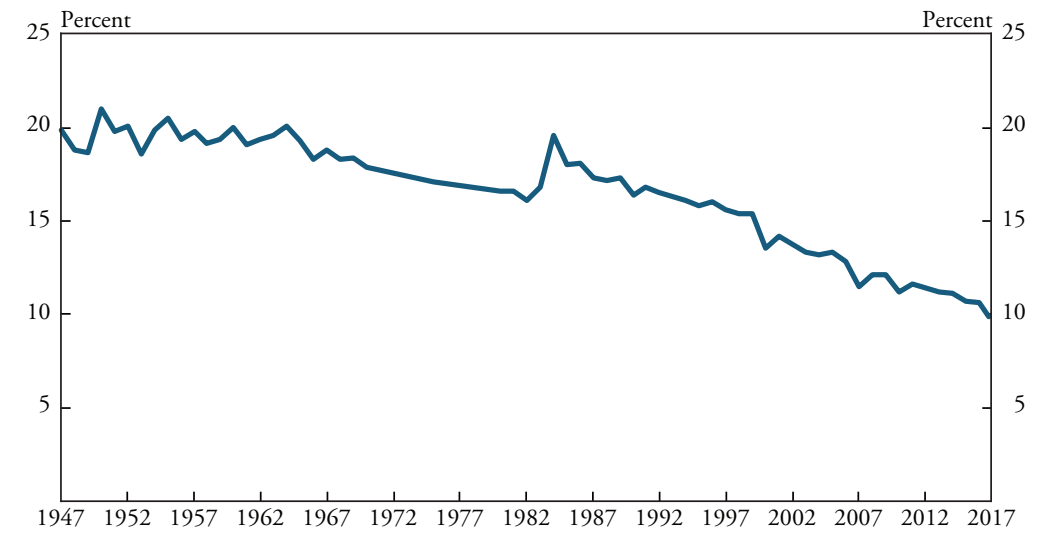

Source: U.S. Census Bureau.

number of personal exemptions claimed approximates the number of individuals who migrated. We use the number of exemptions in our analysis, as it more closely approximates the total number of individuals who moved. Due to the way income tax returns are reported, the filing year actually includes information for the prior year. For this reason, we identify the year in our analysis as the year prior to filing-for example, we identify migration data for 2017 to 2018 as year 2017 .

We use the IRS county-level data to group counties into urban areas known as Core-Based Statistical Areas (CBSAs). ${ }^{1}$ The Census Bureau defines CBSAs as micropolitan or metropolitan depending on the population of urban areas within each county and neighboring counties. Using county-level population data allows us to show domestic migration between urban areas in the country. We label CBSAs as micropolitan (fewer than 220,000 people, such as Shawnee, OK), small urban $(220,000$ to $<1$ million people, such as Omaha-Council Bluffs, NE-IA), medium urban ( 1 to $<4$ million people, such as Kansas City, MO-KS), or large urban (4 million or more people, such as ChicagoNaperville-Elgin, IL-IN-WI).

Table 1 reports population summary statistics of the assigned groups measured in 2000. The majority of the urban areas in the sample are micropolitan, with populations ranging from 13,000 to 214,000. Although the Census Bureau has no official definition of rural areas, many of these micropolitan areas could be considered rural in nature. 


\section{Table 1}

Population of Urban Areas in 2000

\begin{tabular}{l|c|c|c|c}
\hline \multirow{2}{*}{ Urban area } & \multirow{2}{*}{ Number } & Minimum & Median & Maximum \\
\cline { 3 - 5 } & 734 & 12,949 & 54,637 & 213,967 \\
Micropolitan & 134 & 222,407 & 387,899 & 972,501 \\
Small urban & 38 & $1,041,759$ & $1,638,299$ & $3,277,022$ \\
Medium urban & 11 & $4,135,875$ & $4,740,056$ & $18,356,204$ \\
Large urban & &
\end{tabular}

Sources: U.S. Census Bureau and authors' calculations.

\section{Table 2}

Population Turnover Rates (Percent)

\begin{tabular}{l|l|l|c}
\hline \hline Urban area & 2000 & 2017 & Percent change \\
\hline All urban areas (average) & 8.13 & 7.51 & -7.6 \\
Micropolitan & 5.82 & 5.23 & -10.1 \\
Small urban & 7.53 & 6.79 & -9.8 \\
Medium and large urban & 9.19 & 8.50 & -7.5 \\
\hline
\end{tabular}

Sources: IRS, U.S. Census Bureau, and authors' calculations.

When measuring population turnover, we exclude all moves within the same county or CBSA, as these moves are more likely to be housing-related than job-related (Frey 2019). This restriction means that our measures of population turnover are lower than if they were constructed based on all types of moves.

Even so, our measures show that the average population turnover rate in urban areas declined over the past two decades, though the decline was more pronounced for smaller versus larger urban areas. Table 2 reports population turnover rates measured in 2000 and 2017. In 2000 , the average population turnover rate across urban areas was 8.1 percent, meaning that on average, 8.1 percent of the population moved into or out of an urban area. By 2017, the average population turnover rate across all urban areas had declined to 7.5 percent. Turnover rates were highest in larger urban areas in both 2000 and 2017 and lowest in micropolitan areas. In addition, micropolitan areas saw the greatest decline in population turnover from 2000 to 2017 (-10.1 percent).

\section{Population Turnover and Long-Term Growth}

A greater decline in population turnover among less populated areas mirrors a previous finding that these areas have also experienced 
larger declines in business turnover (Brown 2018). Economic theory suggests that business turnover can fuel economic growth by allowing new firms to replace older and potentially less efficient firms. The same may be true for population turnover to the extent that it allows for better matches between employers and employees in the labor market. Indeed, previous research has documented a positive correlation between business turnover and the population growth of urban areas (Hathaway and Litan 2014). Together, declining business and population turnover may suggest that smaller urban areas have become less dynamic.

To examine this possibility, we explore the relationship between the initial population size of urban areas and population turnover as well as the relationship between initial population turnover and subsequent population growth. Chart 2 shows the relationship between urban area population (natural log) in 2000 and population turnover in 2017. The black dashed line slopes upward, indicating that the general relationship between initial population and population turnover in subsequent years is positive. In other words, urban areas with a larger population in 2000 tended to have higher population turnover in 2017.

Given the general differences in population turnover by urban area size noted in the previous section, the relationship between initial population and population turnover may also vary with urban area size. To account for these potential variances, Chart 3 plots initial population and population turnover by urban area size group for micropolitan areas (blue dots), small urban areas (green dots), and medium and large urban areas (orange dots). The steeper dashed regression line for micropolitan areas indicates that these areas have driven the overall positive correlation between population and population turnover. The less steep-but still upward-sloping-dashed regression line for small urban areas indicates that the correlation between initial population and population turnover is much weaker for these areas. Finally, the flat regression line for medium and large urban areas indicates that the correlation between initial population and population turnover in these areas is not discernable from zero. Together, Charts 2 and 3 illustrate that although areas with larger populations tend to have higher population turnover, the strength of this correlation decreases as the population of urban areas increases. 


\section{Chart 2}

Initial Population and Population Turnover

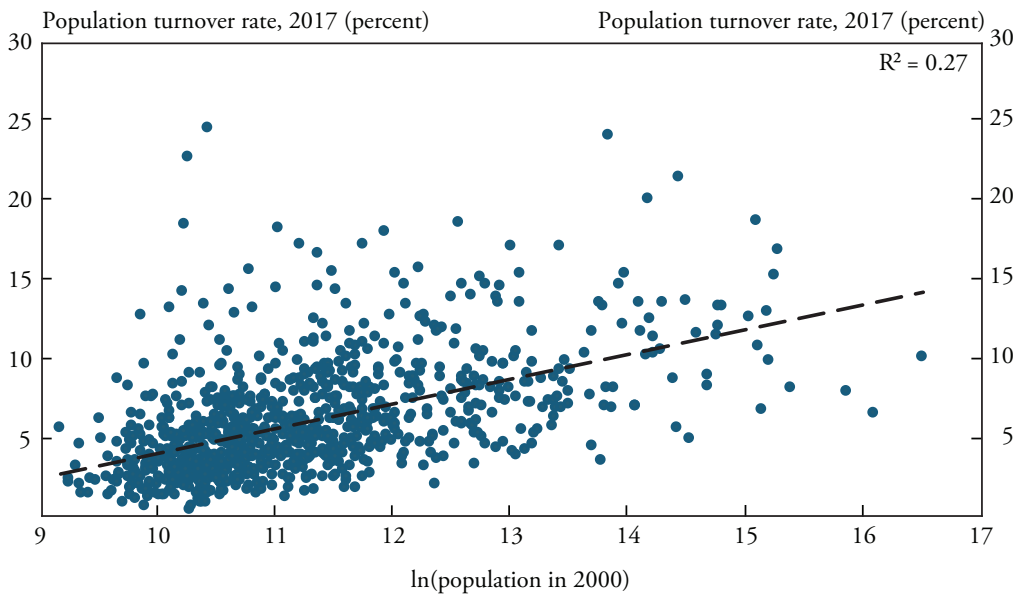

Sources: IRS, U.S. Census Bureau, and authors' calculations.

\section{Chart 3}

Initial Population and Population Turnover by Urban Area Size

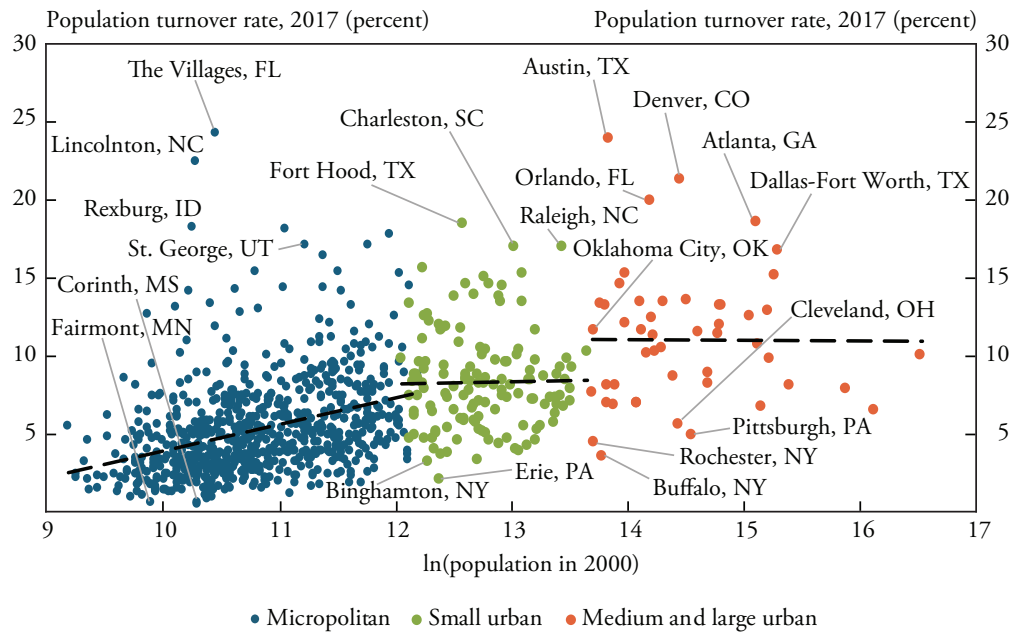

Note: CBSAs are labeled with the names of their primary cities.

Sources: IRS, U.S. Census Bureau, and authors' calculations. 
Several urban areas deviate from the general relationship between initial population and population turnover. For example, the top-left corner of Chart 3 contains areas with relatively smaller populations in 2000 but high population turnover in 2017. One reason for the unusually high population turnover in these areas may be that they have features that make them more attractive places to live (McGranahan, Wojan, and Lambert 2011; Rappaport 2018). For example, many of these areas (The Villages, FL; Lincolnton, NC; Rexburg, ID) are adjacent to larger urban areas, have high natural amenities, or have warmer winters. Conversely, the bottom-left corner of Chart 3 contains areas of similar size but with low population turnover. One reason for the unusually low turnover in these areas may be that they are more dependent on manufacturing, such as Fairmont, MN, and Corinth, MS. These areas may be less attractive to movers because of the long-term decline in some portions of U.S. manufacturing. This pattern of lower turnover in historically manufacturing-heavy urban areas persists across progressively larger urban areas. For example, population turnover was well below the regression line in Erie, PA; Pittsburgh, PA; Buffalo, NY; and Rochester, NY, all of which are in the Rust Belt.

On the other end of spectrum, population turnover was well above the regression line in the large urban areas of Austin, TX, and Denver, $\mathrm{CO}$. These areas in particular are likely to have benefitted from the knowledge economy, in which innovative firms and innovative workers increasingly cluster in larger urban areas with high amenities (Moretti 2012).

A natural question is whether differences in turnover rates across urban areas are due more to differences in inflows versus outflows of people. One way to gauge the quantitative importance of inflows and outflows in generating the observed differences in turnover rates is to look at the correlation between inflows and outflows. In unreported results, we find that the correlation is very strong, ranging from 0.95 for micropolitan areas up to 0.98 for large urban areas. This strong correlation suggests that across the size distribution of urban areas, locations with high inflow rates also have high outflow rates, and areas with low inflow rates also have low outflow rates. Thus, population turnover rates are a useful measure of labor market adjustment even without distinguishing between inflows and outflows. 
Nevertheless, decomposing turnover rates into inflows and outflows may be useful to the extent that the origins and destinations of these flows differ in meaningful ways. Population turnover rates alone cannot reveal, for example, whether residents of small urban areas are primarily moving to larger urban areas; only a detailed decomposition of inflow rates by origin area size would capture this information. Decomposing both inflow and outflow rates in this way may provide additional insight into the future of the labor market in different urban areas. Previous research has highlighted the higher average productivity of workers in larger urban areas (Glaeser and Saiz 2004; Henderson 2007). Workers take the knowledge and capabilities that influenced their productivity when they move. As a result, an urban area that is primarily losing residents to larger areas and gaining residents from smaller areas may subsequently see less productive matches between employers and employees.

To explore whether inflows and outflows to urban areas indeed differ by origin or destination size, we compare select urban areas with similar population turnover rates in 2017 but different initial populations in 2000. Specifically, we compare the urban areas of St. George, UT (population 75,396); Charleston, SC (population 456,261); and Dallas-Fort Worth, TX (population 4,431,182). The population turnover rates for all three urban areas are similar in 2017, ranging from 16.6 to 17.0 percent. However, the composition of the turnover-that is, the inflows and outflows broken down by origin or destination size-is very different.

Panels A and B of Chart 4 decompose turnover into the inflow and outflow rates of these three urban areas by origin or destination size. The composition of the inflow rate for Dallas-Fort Worth is substantially different from the St. George and Charleston urban areas. The orange bar in Panel A shows that Dallas-Fort Worth's overall inflow rate is primarily driven by people moving from other medium and large urban areas. In contrast, the inflow rates in St. George and Charleston are primarily driven by people moving from small urban areas. The composition of outflow rates follows a similar pattern (Panel B). DallasFort Worth's overall outflow rate is primarily driven by people moving to other medium and large urban areas, while the outflow rates in St. George and Charleston are primarily driven by people moving to 


\section{Chart 4}

\section{Inflow and Outflow Rates of Select Urban Areas}

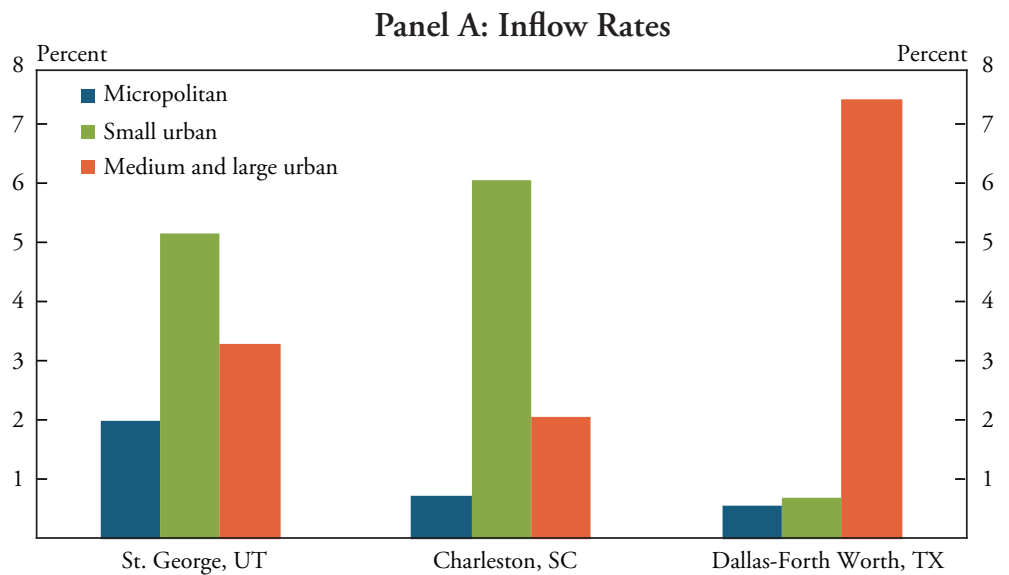

Panel B: Outflow Rates

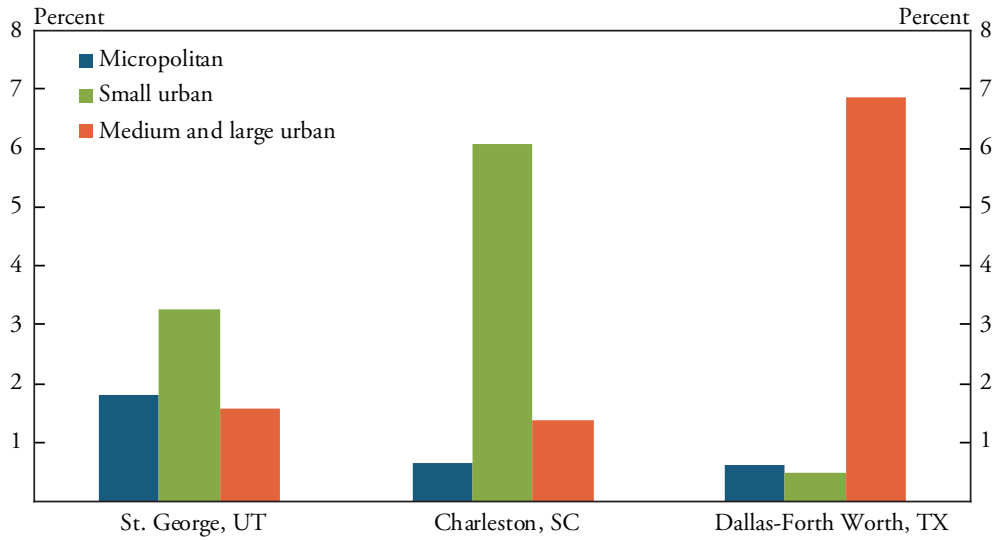

Sources: IRS, U.S. Census Bureau, and authors' calculations.

small urban areas. This comparison illustrates that places like DallasFort Worth, which have higher contributions of inflows and outflows from medium and large urban areas, likely experience different labor market adjustments. Much of the service sector is increasingly based on knowledge, idea exchange, and agglomeration; shifting the economic base in such a way highly favors larger urban areas (Henderson 2007; Moretti 2012).

The composition of population turnover implicitly captures differences in the knowledge and experience of people as they move from one 
area to another. To the extent that moves are job-related, any persistent differences in the composition or level of population turnover across urban areas may have long-term implications for growth in those areas. To explore this possibility, we calculate the correlation between an urban area's population turnover in 2000 and subsequent population growth from 2000 through 2017. The upward-sloping dashed regression line in Chart 5 shows that an urban area's initial population turnover rate is positively correlated with subsequent population growth. In other words, urban areas with higher population turnover rates in 2000 tended to have greater population growth over the next 17 years. $^{2}$

As with the correlation between initial population and population turnover, some urban areas are outliers. For example, the micropolitan area of Williston, ND, has higher population growth than might be expected given its lower initial population turnover rate. However, Williston, ND, was the epicenter for the shale oil boom in the Bakken formation over the past decade, which led to a large increase in available jobs (Maniloff and Mastromonaco 2017). Similarly, The Villages, FL, and Lincolnton, NC, had higher population growth than might be expected. However, as mentioned previously, these are areas with warmer winters and high natural amenities, which may help explain their robust growth.

Previous research has documented that due to the self-sustaining nature of economic development, urban areas that are initially similar can become very different over time as small differences are magnified (Moretti 2012). As an example, we compare the urban areas Austin, TX; Oklahoma City, OK; and Buffalo, NY. While the three areas had similar initial populations in 2000, their initial population turnover rates were different, potentially explaining their subsequent differences in growth. Chart 5 shows that Austin had both the highest initial population turnover rate in 2000 and the highest population growth from 2000 to 2017. Likewise, Buffalo had the lowest initial population turnover rate and the lowest subsequent population growth.

Together, our findings suggest differences in population turnover across urban areas may be an important factor in explaining differences in population growth. To the extent population turnover captures labor market adjustment, our findings may help explain why some urban 


\section{Chart 5}

Population Turnover versus Population Growth by Urban Area

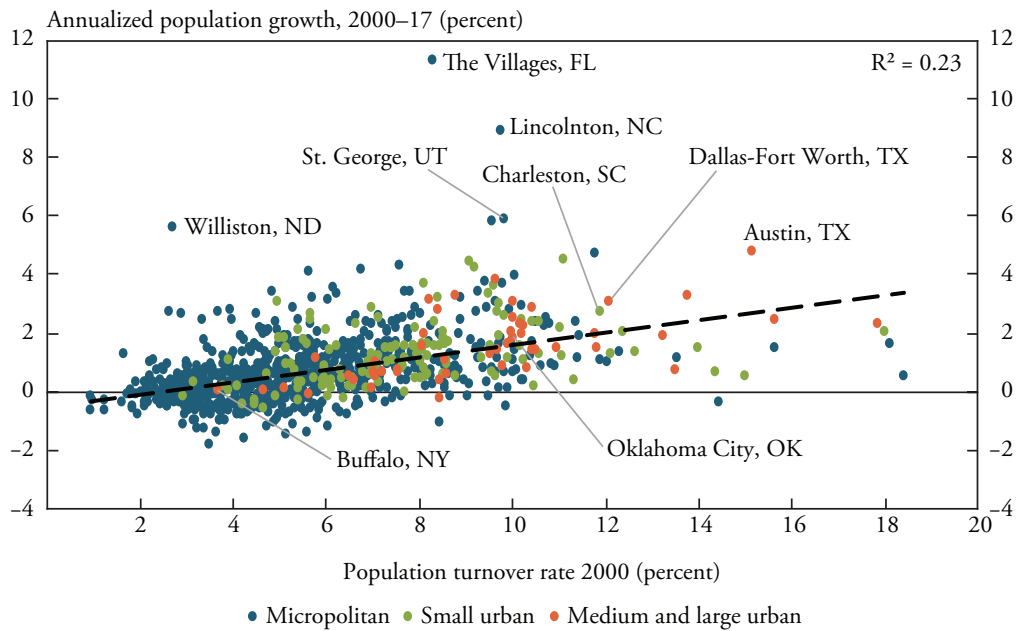

Note: CBSAs are labeled with the names of their primary cities.

Sources: IRS, U.S. Census Bureau, and authors' calculations.

areas, despite a similar initial size, experience different growth trajectories. These differences are likely amplified in areas where the knowledge economy accounts for a greater share of economic activity, as innovative firms and innovative workers cluster in larger urban areas where population turnover is highest.

\section{Conclusion}

U.S. domestic migration has declined dramatically over the past several decades, leading to differences in population turnover across urban areas of different size. We measure population turnover using data from the IRS and find that population turnover is higher in larger urban areas. In addition, we find that higher population turnover, a proxy for labor market adjustment, is positively associated with population growth over a longer time horizon. Higher population turnover may facilitate better matches between employer and employee. Higher population turnover may also help with the dissemination of knowledge between people and firms as people come into an area with new ideas or take ideas with them to other locations. 
Given the differences in population turnover between the smallest and largest urban areas, smaller locations may be at risk of lower levels of labor market adjustment. As a result, these areas may also be more likely to struggle in the event of a future economic downturn. Recessions often lead to a redistribution of resources and activity across sectors in the economy, and labor markets in areas with higher population turnover may be able to adjust to these changes more quickly. If the gap between the turnover rates of small and large urban areas persists or widens further, the gap between their economic fortunes may widen as well. 


\section{Endnotes}

${ }^{1}$ The 2003 CBSA definitions, released by the Office of Management and Budget, were used to construct urban area measures of business turnover. Metropolitan statistical areas have at least one urbanized area with a population of 50,000 or greater plus "adjacent territory that has a high degree of social and economic integration with the core as measured by commuting ties." Micropolitan statistical areas have at least one urban area with a population between 10,000 and 50,000 plus "adjacent territory that has a high degree of social and economic integration with the core as measured by commuting ties."

${ }^{2}$ The correlation is similar in size if estimated separately for micropolitan, small, and medium and large urban areas. 


\section{References}

Autor, David H., David Dorn, and Gordon H. Hanson. 2013. "The China Syndrome: Local Labor Market Effects of Import Competition in the United States." American Economic Review, vol. 103, no. 6, pp. 2121-2168. Available at https://doi.org/10.1257/aer.103.6.2121

Autor, David H., David Dorn, Gordon H. Hanson, and Jae Song. 2014. "Trade Adjustment: Worker-Level Evidence.” Quarterly Journal of Economics, vol. 129, no. 4, pp. 1799-1860. Available at https://doi.org/10.1093/qje/qju026

Blanchard, Olivier Jean, and Lawrence F. Katz. 1992. "Regional Evolutions." Brookings Papers on Economic Activity, vol. 1992, no. 1, pp. 1-75. Available at https://doi.org/10.2307/2534556

Brown, Jason P. 2018. "The Widening Divide in Business Turnover between Large and Small Urban Areas." Federal Reserve Bank of Kansas City, Economic Review, vol. 103, no. 3, pp. 5-25. Available at https://doi.org/10.18651/ $\mathrm{ER} / 3 \mathrm{q} 18$ Brown

Dao, Mai, Davide Furceri, and Prakash Loungani. 2017. "Regional Labor Market Adjustment in the United States: Trend and Cycle." Review of Economics and Statistics, vol. 99, no. 2, pp. 243-257. Available at https://doi.org/10.1162/ REST_a_00642

Dennis, Benjamin N., and Talan B. Iscan. 2007. "Productivity Growth and Agricultural Out-Migration in the United States." Structural Change and Economic Dynamics, vol. 18, no. 1, pp. 52-74. Available at https://doi.org/10.1016/j. strueco.2005.11.003

Frey, William H. 2019. "For the First Time on Record, Fewer than 10\% of Americans Moved in a Year." Brookings Institution, The Avenue (blog), November 22.

Glaeser, Edward. 2011. Triumph of the City. New York: Penguin Press.

Glaeser, Edward L., and Albert Saiz. 2004. "The Rise of the Skilled City." Brookings-Wharton Papers on Urban Affairs, pp. 47-105.

Hathaway, Ian, and Robert E. Litan. 2014. "What's Driving the Decline in the Firm Formation Rate? A Partial Explanation.” Brookings Institution, November.

Henderson, J. Vernon. 2007. "Understanding Knowledge Spillovers." Regional Science and Urban Economics, vol. 37, no. 4, pp. 497-508. Available at https:// doi.org/10.1016/j.regsciurbeco.2006.11.010

Kaplan, Greg, and Sam Schulhofer-Wohl. 2017. "Understanding the Long-Run Decline in Interstate Migration.” International Economic Review, vol. 58, no. 1, pp. 57-94. Available at https://doi.org/10.1111/iere.12209

Maniloff, Peter, and Ralph Mastromonaco. 2017. "The Local Employment Impacts of Fracking: A National Study." Resource and Energy Economics, vol. 49, pp. 62-85. Available at https://doi.org/10.1016/j.reseneeco.2017.04.005

McGranahan, David A., Timothy R. Wojan, and Dayton M. Lambert. 2011. "The Rural Growth Trifecta: Outdoor Amenities, Creative Class and Entrepreneurial Context." Journal of Economic Geography, vol. 11, no. 3, pp. 529-557. Available at https://doi.org/10.1093/jeg/lbq007

Molloy, Raven, and Christopher Smith. 2019. "U.S. Internal Migration: Recent Patterns and Outstanding Puzzles." Prepared for Federal Reserve Bank of Boston conference, "A House Divided: Geographic Disparities in TwentyFirst Century America," Boston, MA, October 4-5. 
Molloy, Raven, Christopher L. Smith, and Abigail Wozniak. 2011. "Internal Migration in the United States." Journal of Economic Perspectives, vol. 25, no. 3, pp. 173-196. Available at https://doi.org/10.1257/jep.25.3.173

Moretti, Enrico. 2012. The New Geography ofJobs. Boston: Houghton Mifflin Harcourt.

Partridge, Mark D., and Dan S. Rickman. 2006. "An SVAR Model of Fluctuations in U.S. Migration Flows and State Labor Market Dynamics." Southern Economic Journal, vol. 72, no. 4, pp. 958-980. Available at https://doi. org/10.2307/20111863

Partridge, Mark D., Dan S. Rickman, M. Rose Olfert, and Kamar Ali. 2012. "Dwindling U.S. Internal Migration: Evidence of Spatial Equilibrium or Structural Shifts in Local Labor Markets?" Regional Science and Urban Economics, vol. 42, no. 1-2, pp. 375-388. Available at https://doi.org/10.1016/j. regsciurbeco.2011.10.006

Rappaport, Jordan. 2018. "The Faster Growth of Larger, Less Crowded Locations.” Federal Reserve Bank of Kansas City, Economic Review, vol. 103, no. 4, pp. 5-38. Available at https://doi.org/10.18651/ER/4q18Rappaport 